COLLEGE OF AGRICULTURE AGRICULTURAL EXPERIMENT STATION BERKELEY, CALIFORNIA

\title{
TURKISH TOBACCO CULTURE, CURING, AND MARKETING
} By WARREN T. CLARKE

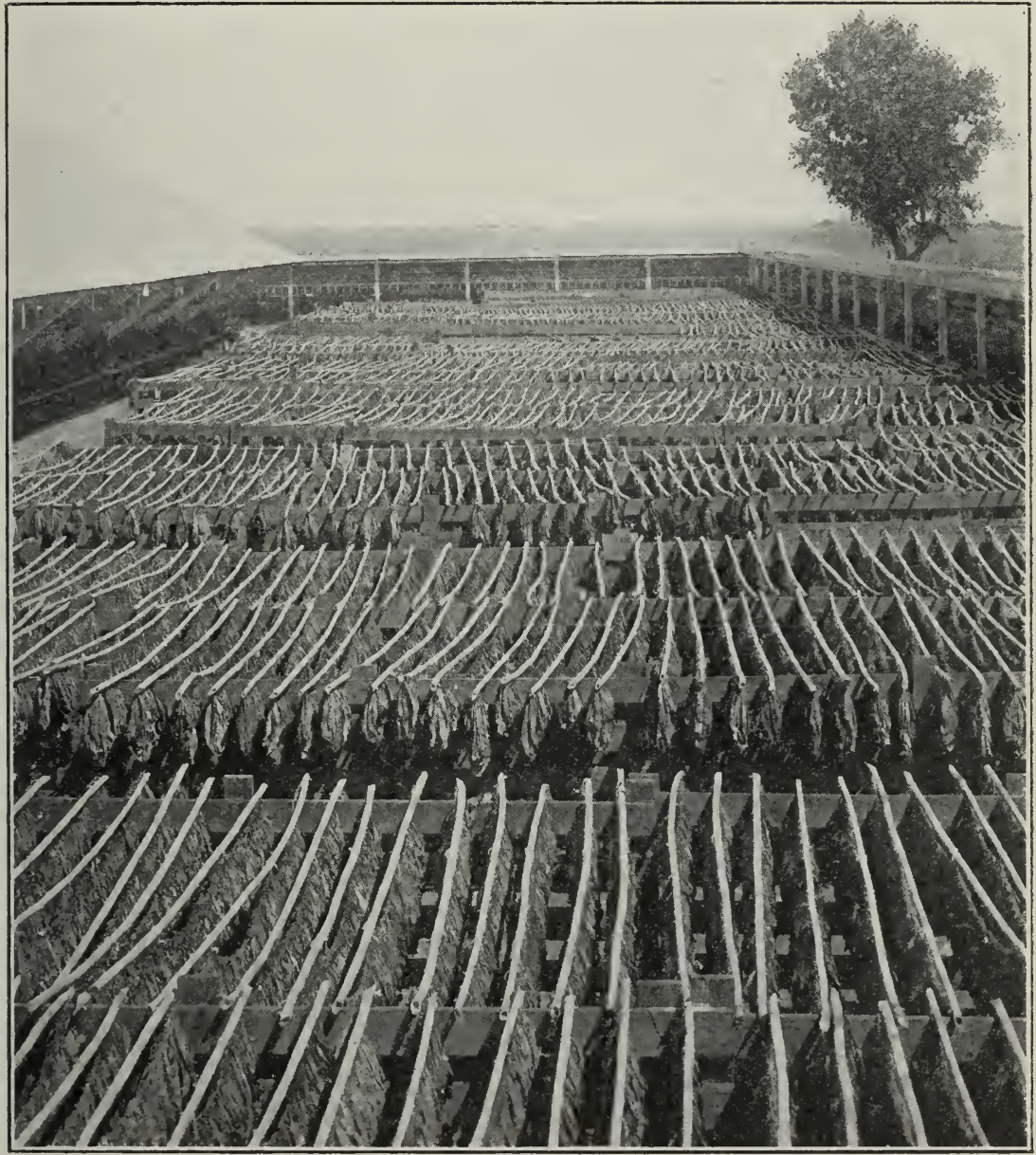

Sun-curing Turkish Type Tobacco. Note use of giant reed poles.

BULLETIN No. 366

JUNE, 1923

UNIVERSITY OF CALIFORNIA PRESS

BERKELEY, CALIFORNIA 
David P. Barrows, President of the University.

\section{EXPERIMENT STATION STAFF}

\section{HEADS OF DIVISIONS}

Thomas Forsyth Hunt, Dean.

EDWARD J. WICKSON, Horticulture (Emeritus).

- Director of Resident Instruction.

C. M. HARING, Veterinary Science, Director of Agricultural Experiment Station.

B. H. Crocheron, Director of Agricultural Extension.

C. B. Hutchison, Plant Breeding, Director of the Branch of the College of Agriculture at Davis.

H. J. Webber, Sub-tropical Horticulture, Director of Citrus Experiment Station. William A. Setchell, Botany.

MYER E. JAFFA, Nutrition.

RALPh E. SMith, Plant Pathology.

John W. Gilmore, Agronomy.

Charles F. Shaw, Soil Technology.

JoHn W. GregG, Landscape Gardening and Floriculture.

Frederic T. Bioletti, Viticulture and Fruit Products.

Warren T. Clarke, Agricultural Extension.

Ernest B. Babcock, Genetics.

Gordon H. True, Animal Husbandry.

WALter Mulford, Forestry.

JAmes T. BARrett, Plant Pathology.

W. P. Kelley, Agricultural Chemistry.

H. J. Quayle, Entomology.

ELwOod MEAD, Rural Institutions.

H. S. REed, Plant Physiology.

L. D. BATChelor, Orchard Management.

W. L. Howard, Pomology.

*Frank Adams, Irrigation Investigations.

C. L. Roadhouse, Dairy Industry.

R. L. AdAMs, Farm Management.

W. B. Herms, Entomology and Parasitology.

John E. Dougherty, Poultry Husbandry.

D. R. Hoagland, Plant Nutrition.

G. H. HART, Veterinary Science.

L. J. Fletcher, Agricultural Engineering.

Edwin C. Voorhies, Assistant to the Dean.

* In coöperation with Division of Agricultural Engineering, Bureau of Public Roads, U. S. Department of Agriculture. 


\title{
TURKISH TOBACCO CULTURE, CURING, AND MARKETING ${ }^{1}$
}

\author{
BY WARREN T. CLARKE
}

CONTENTS

PAGE

General Discussion

Varieties and Improvement through Selection

Climate.

Soils.

Preparation of the Land.

Cultivation-Irrigation

The Seed Bed.

Transplanting.

Field Treatment and Picking..................

First Operation in Curing.

Curing Barns

Some Suggestions.

Fermentation, Grading, and Marketing.....

Methods of Fermenting Turkish Tobacco.

Bulk Fermentation.

Bale Fermentation

Marketing Turkish Type Tobacco

Pests.

Appendix

The tobacco plant (Nicotiana tabacum) is a native of the western hemisphere. It takes its botanical name from Jean Nicot who introduced its use to the French court between 1555 and 1560. It takes its specific name from a tube called the 'tabaco,' used by the natives of Haiti for smoking and for taking snuff. The plant has a rather close family relationship to the tomato and potato and to the so-called nightshades.

The first Caucasian visitors to the western continents found the natives using the leaves of this plant for smoking, chewing, and snuffing. It was highly esteemed by these native Indians and was considered by them to have a certain medicinal value. They understood well the process of curing the leaf and there is small doubt that the product turned out by them was of good quality. In some cases the smoking of tobacco assumed a certain ceremonial value.

1 Acknowledgment is made to Daniel S. Neuman, of Napa, California, for valuable suggestions and material furnished; to Mr. Alfred Aram, President, Associated Tobacco Growers, Inc., of California, for assistance rendered and for the section on fermentation, grading, and marketing; to Mr. E. J. Moorehead of Crows Landing for valuable data furnished and to members of the staff of the Experiment Station who have read and criticised this manuscript. 
The smoking of the "pipe of peace" meant a sacred ratification of treaties looking to a cessation of hostilities between tribes and an encling of wars between the colonists and the Indians. The English co.onists soon began to use tobacco and it came to fill a rather important place in the colonies as a medium of barter and exchange. It soon found its way to England and to the continent of Europe through trade channels and has since come into general use throughout the world.

The alkaloid, nicotine, which is the distinguishing feature of tobacco, is a violent poison in the concentrated form. In the cured leaf but minute quantities of this alkaloid are found and the material however used becomes a very mild narcotic. It has, however, enough of this narcotic effect to be habit-forming, and perhaps this fact accounts for the very wide use of tobacco all over the world.

The general demand for the cured leaf stimulated tobaceo growing in America and generally throughout the islands contiguous to our southeastern coast until now the growing (fig. 1) and curing of tobacco is an extremely important industry on this continent and in the islands of Cuba, Haiti, and others of the West Indian group. Some idea of this importance may be gathered from the fact that nearly seven hundred million pounds of the cured leaf is annually used in the United States in the manufacture of cigars, cigarettes, snuff, and smoking and chewing tobacco.

Not alone in this country, however, is tobacco an important agricultural crop. It is grown in greater or less quantities in other countries, particularly in certain regions in southeastern Europe, Asia Minor, Servia, the Levant generally, and in Greece. But the origin of practically all the varieties now grown throughout the world for commercial purposes may be traced to the continent of America. Some two hundred years ago tobacco growing began in the regions designated, seed from America being used. This industry was begun and carried forward under Turkish auspices and the term "Turkish tobacco" was early applied to the product. The Turkish taste was and is for a very mild tobacco, of good aroma and bouquet, mellow and of good burning qualities. It is used by the people where it is grown almost exclusively for cigarettes and is esteemed all over the world for its great delicacy and mildness. Some twenty-five million pounds of this so-called Turkish tobacco is annually imported to this country and used in the manufacture of cigarettes.

Some twenty-five to thirty years ago the growing of Turkish tobacco was begun in California. Occasional individuals, mainly Armenians and Greeks, succeeded in getting seed from their native 
lands. This was a difficult matter because of the embargo placed upon the exportation of seed, and devious means of evasion were employed. It seemed to satisfy these early importers that the seed came from known districts but there was no certainty that the seed was from plants that were true to type and not cross-pollinated. The plants were given the name of the district from which the seed came, such as Samsoon (Samsoun, Sampsoon), Cavalla, Smyrna, etc. As

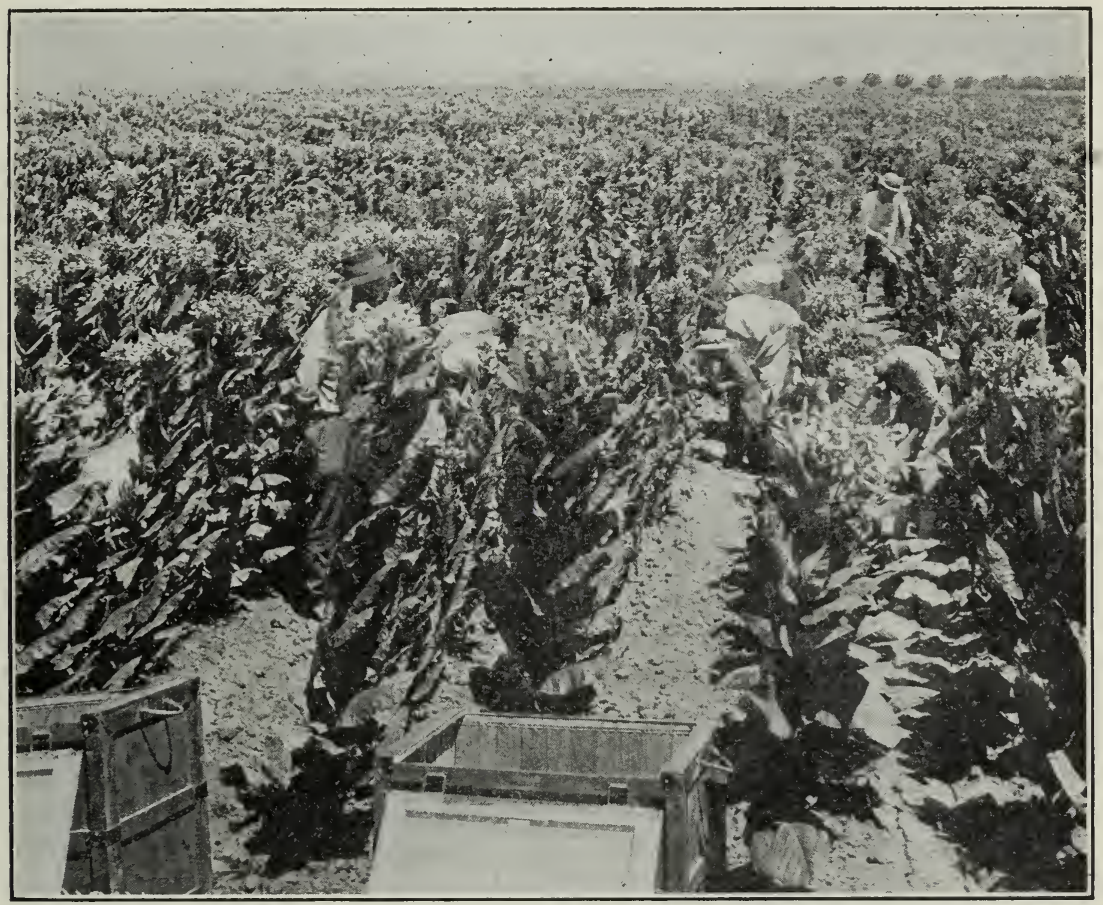

Fig. 1.-A field of Turkish tobacco, Yolo County, California. Carrying crates in foreground.

a matter of fact, the plants grown showed no uniformity of type. From the same lot of seed would come plants showing the rather large, fleshy, sessile leaves of Samsoon through many variations to the cleanly petiolate leaves of Dubaka (figs. 2-3). These early importers of seed and growers of tobacco practiced no selection of plants for seed purposes nor did they adequately guard against crosspollination. The result was a jumble of types, good, indifferent, and poor. Curing methods were faulty and with an occasional exception the final product was harsh and unusable save for low grade products. 
Somewhat later, approximately fifteen to twenty years ago, an apparently serious effort to produce Turkish tobacco was begun by the American Tobacco Company, the so-called Trust. Their plantings, which were quite extensive, were made in Tulare County about the settlement of Yettem and near Exeter. In this set of plantings Greek and Armenian farmilies that had been tobacco growers in the old country were placed upon the land and they were encouraged in every way to continue their hereditary occupation as growers and curers of tobacco. It was reported that for some cause not fully explained but evidently economic, this attempt was not a great success. On the dissolution of the so-called trust into its component parts the interest in the work languished and the experiment ended.

About 1908 the so-called "Exeter Tobacco Ranch," reputed to be an enterprise of the American Tobacco Company, produced some very fair tobacco on its properties near Exeter. From the same source was issued about 1912 an undated pamphlet entitled "Information on the Culture of Tobacco in California." In this pamphlet the writers go very fully into the matter of culture and curing. They state that "The final result expected is that the general farmer will, aided by our experiments, produce in quality, tobacco that will interest manufacturers and on its own merits command a profitable price for the farmer." For unexplained reasons the pamphlet was quickly withdrawn from circulation. Though it had but a limited circulation so far as we can learn, it undoubtedly helped to stimulate interest in this crop because of the belief expressed in the possibilities of producing a good grade of Turkish tobacco in this state. For the last ten years plantings of Turkish tobacco both commercial and experimental have been made in many of the counties of the state and our knowledge of both cultural and curing methods has increased greatly. The success of the business depends mainly on economic factors, though the application of improved cultural and curing methods is necessary.

It is to be noted that the pioneers in this work had great diffculty in disposing of the product. This is traceable to two causes. In the first place, owing to improper growing methods, failure to select s`ed-producing plants and hence mixture of types, poor and incomplete curing and lack of aging, the product offered for sale usually did not compare favorably with the imported tobacco. In the second place there has been an evident reluctance on the part of manufacturers of tobaceo products to use the California product to any great extent, even when it is of good quality. These two 
facts have caused many growers to give up the attempt to establish the new industry.

An interesting fact in connection with this lack of demand for California-grown tobacco is that it resulted in many thousands of pounds of fair tobacco being stowed away in barns and almost forgotten. The tobacco was forced by circumstances into a protracted aging which resulted in great improvement of quality.

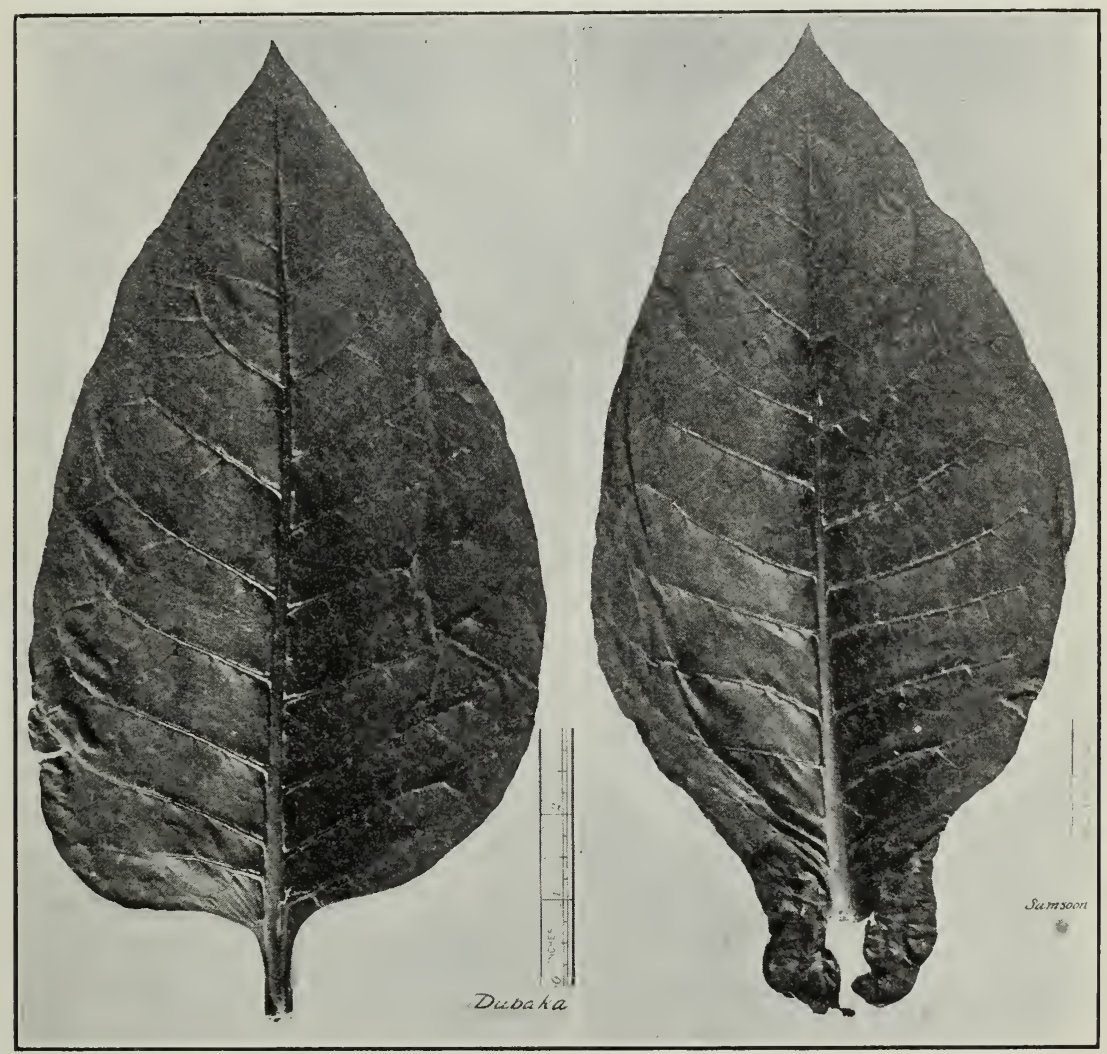

Fig. 2.-Dubaka leaf closely approaching Cavalla type.

Fig. 3.-Samsoon leaf. Note sessile character.

Gradually the fact has become recognized that the California growers would have to enter the manufacturing field themselves to obtain an adequate recognition of the good quality of their product and a fair money return. Early in 1922 a company was organized to handle California-grown Turkish tobacco. This company, a pioneer in a new field, is now turning out in the neighborhood of a half-million cigarettes monthly. Their product is finding a ready 
sale in the retail market. The enterprise, though small, indicates what can be done and it should be expanded largely but not as a private enterprise. Undoubtedly the consuming public appreciates the finished product of our California Turkish tobacco growers, curers and manufacturers.

There is naturally room for much improvement all along the line and it is hoped this publication in presenting the facts brought out by experimental work and by commercial planters may aid in establishing the industry on a firm agricultural base.

\section{VARIETIES AND IMPROVEMENT THROUGH SELECTION}

The term "Turkish tobacco" applies to the varieties of tobacco grown mainly in southern Macedonia, Turkey, Asia Minor, Servia, Greece, and the Levant generally. It is characteristically small leafed as compared with Dark tobacco, light leafed Burley, Sumatra seed tobacco, and Cuban tobaccos. These varieties are the main reliance of the tobacco growers of the eastern states and are grown in the eastern tobacco sections to the exclusion of the Turkish type. The usable leaf of the Turkish tobacco grown in California ranges in length from two inches to about ten inches and in width from one inch to six inches. This range in size is found on the same plant from the largest leaves at the bottom to the smallest leaves at the top or blossom end of the plant (fig. 4). By way of comparison the leaf of eastern types of tobacco frequently reaches as great a length as twenty inches with a corresponding width of twelve inches.

The leaf of Turkish tobacco is small and of fine texture. Fineness of grain and smallness of ribs are of great importance in determining the value of Turkish tobacco. The cured leaf of Turkish tobacco is superior to the leaves of other types in the delicate quality of its aroma and bouquet.

The difference noted above will serve to distinguish the leaf of Turkish type from the leaves of other types of tobacco grown in the United States. In the Turkish group are many variations which can be traced in California to the soil and climatic conditions under which the tobacco is grown and to cross-pollination (fig. 5). In the first serious attempts to produce Turkish leaf in California some twenty-five to thirty years ago seed was obtained, as previously stated, by various and sometimes devious ways from different sections of Macedonia, Turkey, Asia Minor, Servia and Greece. The principal varieties, so-called, of which seed was imported were Samsoon (Sampsoon, Samsoun), Cavalla, Bafra, Dubaka, and Smyrna. It is im- 


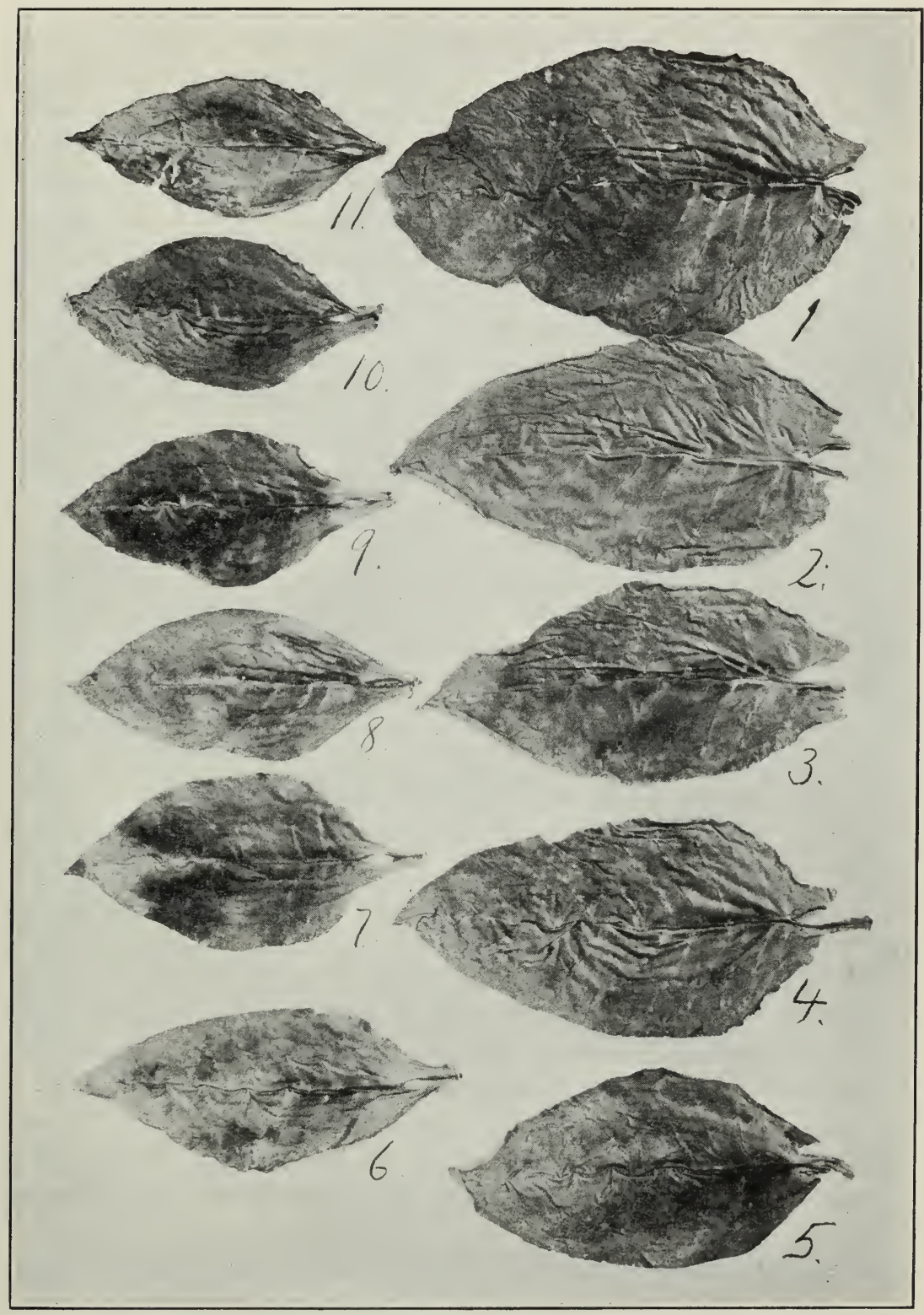

Fig. 4.-Sun cured leaves. 1-2, sand leaves; $3-4$, basma; 5-6-7, gubec; 8-9, ooch-alte; 10-11, ooch. The names are those used to designate character of leaf and position on plant "ooch" being the highest. 
portant to note that these names indicate districts where the leaf is grown and cured and, as we now know, do not mean distinct varieties of tobacco. Any of these varieties may change in character to some extent if the district to which it is brought differs from the district in which it was originally grown in soil or climate or cultural methods, or if cross-pollination occurs. Further, even when the exchange of seed is merely from one district to another, the product will gradually assume other characters than those of the district where it was originally grown. This sensitiveness of the Turkish tobacco plant to its environment and to the care it receives is very marked and together with cross-pollination has resulted in the jumble of types grown in California. Indeed there is not now to be found here any considerable quantity of any of the so-called varieties noted above, but each district in the state where Turkish tobacco has been grown has developed a type of its own differing materially from the original. In some cases this variation has resulted in improvement, in others in deterioration.

The grower of tobacco should know the local conditions and be prepared to meet them by developing suitable variations of high quality. Experiments made by Shamel $^{2}$ with the tobaccos of the Atlantic states showed great virility and viability in seed from selfpollinated flowers. The desirable features, if such were present, were transmitted through the seed, as were the undesirable features. This teaches that by means of proper, well directed seed selection a plant of high quality can be developed and maintained. Shamel's method was, briefly, as follows:

First, Selection.-Plants that show the characters desired by the grower should be chosen while growing in the field. Size of leaf; color of leaf at tip as ripening approaches; fineness of leaf texture (a thick, fleshy leaf is not satisfactory when dealing with Turkish tobacco); small, fine veins or ribs; early maturity; comparative absence of suckers growing out of the plant at leaf bases; all these items should be considered when choosing or selecting plants as seed producers. The selected plants should be well marked so that when priming begins the leaf pickers will allow their leaves to remain on the plant.

Second, Isolation.-The grower should watch these selected plants closely and when the blossom panicle forms should carefully cut off one or two whorls of leaves immediately below the beginning flowers.

2Shamel, Archibald D. The Improvement of Tobacco by Breeding and Selection. Year Book of the Department of Agriculture, 1904, pp. 435-452. 
The operator should provide himself with a number of paper bags of the kind that when open the bottom assumes an angular roof-like form. As soon as the first blossom shows color the panicle should be covered with a paper bag. This should be brought together about the plant below the blossoms and lightly tied so as to exclude bees and other pollen bearing insects. These plants should

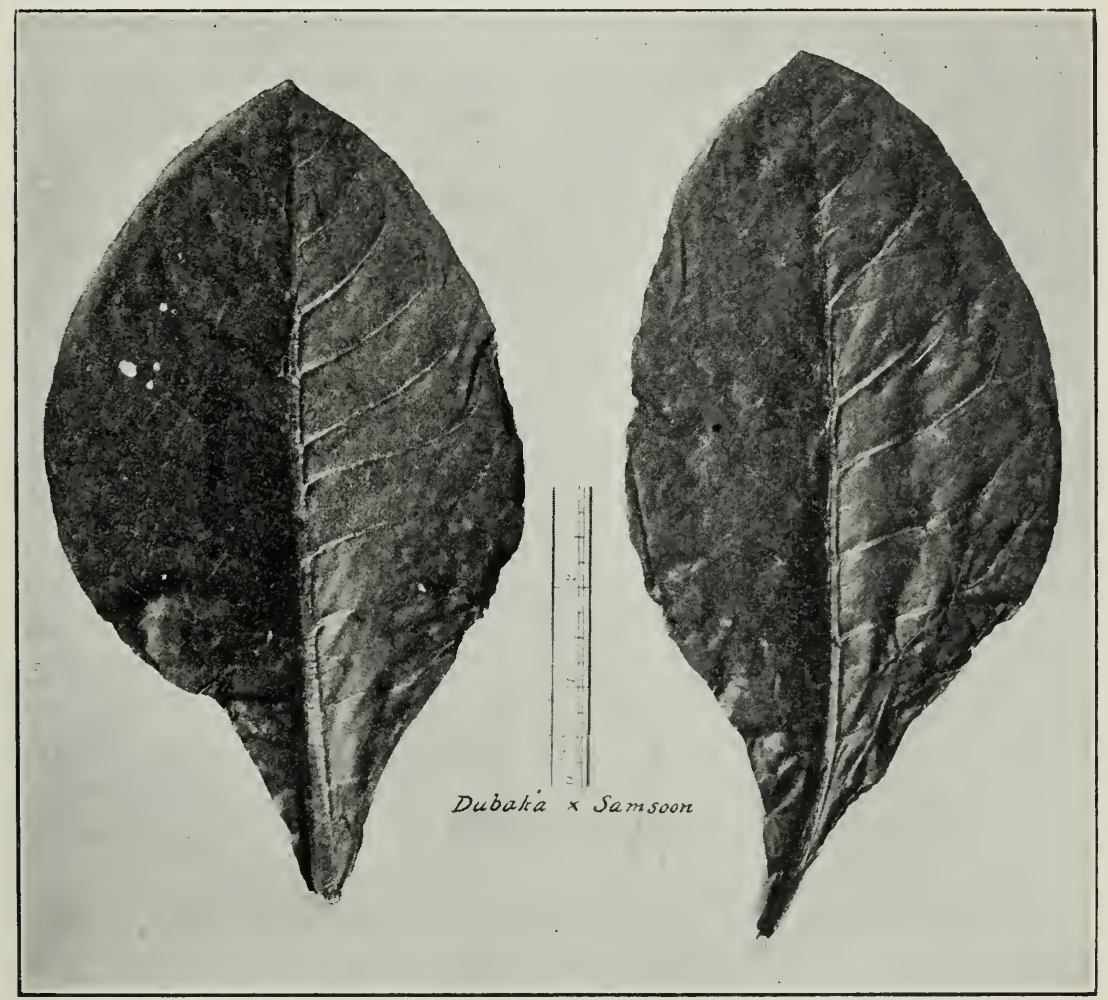

Fig. 5.-Hybrids, Samsoon x Dubaka. Occasional desirable types are thus produced.

be watched carefully and the paper bags occasionally raised slightly and retied so that the blossoms may have ample room for expansion. The leaves should not be removed from the seed plants, and suckers should be pinched out as soon as they appear, as the full strength of the plant should go into seed production.

Though the tobacco plant is a prolific producer of seed, as many as 1000 to 1500 seeds maturing to each capsule, still a comparatively large number of plants should be selected so that there will be no possibility of shortage of seed for the next year's planting. Ripeness 
is determined by the capsules turning brown and brittle. When this stage has been attained the capsules can be removed green or unripe ones being discarded, placed in a bag, and the bags should be of muslin, close-woven, and without holes. The partly filled bags should be hung in a cool, dry, well ventilated place until the capsules break easily. Then the bags, tightly closed, can be beaten with a padded paddle so as to thoroughly break up the capsules and thus liberate the seed. The whole contents of the bag can then be poured out on a sieve of rather small mesh and the loose seed sifted into some sort of container. The seed is now ready for dry storage until seeding time comes again. If the seed is intended for sale it should be cleaned by repeated screening in a light draft. Care must be taken not to make this too strong as the seed can be easily blown away. In some cases seed is cleaned by pouring it into water. The chaff and light seeds float while the good seed sinks. If this process is followed, the water, chaff, and light seed should be poured off as soon as possible and the good seed drained and dried in the shade. Unless the seed is to be used immediately the drying should be very carefully done as damp seed soon moulds.

It should be noted that the persistance of type in self-pollinated, selected Cuban tobacco is emphasized by the studies of Hasselbring ${ }^{3}$ who finds that environment has little if anything to do with the breaking up of types. This does not seem to coincide with our California field experience.

The breaking-up of type when cross-pollination occurs is noted in the studies of California-grown tobacco made by Setchell, Goodspeed, and Clausen. ${ }^{4}$ All of this seems to emphasize the necessity for selection.

By means of careful selection, isolation, and care of the seed the planter should be able to develop plants that give a high grade product uniformly throughout his plantation. There is no doubt that this apparently extreme care pays.

${ }^{3}$ Heinrich Hasselkring types of Cuban Tobacco. The Botanical Gazette, (The University of Chicago), vol. 53, No. 2, February, 1912, pp. 113-126, plates IV-X.

4 Setchell, W. A., Goodspeed, T. H., and Clausen, R. E., Inheritance in Nicotiana tabacum, Univ. Calif. Publ. Bot., vol. 5. pp. 457-582, 2 figures in text, plants 55-85, April 14, 1922. 


\section{CLIMATE}

The climatic conditions of the valleys of the Sacramento and the San Joaquin rivers have been found to be only fairly satisfactory for tobacco growing. While it must be acknowledged that the extremely high temperature sometimes experienced in these valleys, together with the lack of atmospheric humidity, render the task of producing a good tobacco difficult, still fairly good results have been obtained in Placer, (fig. 6) Sutter, Yolo, Sacramento, San

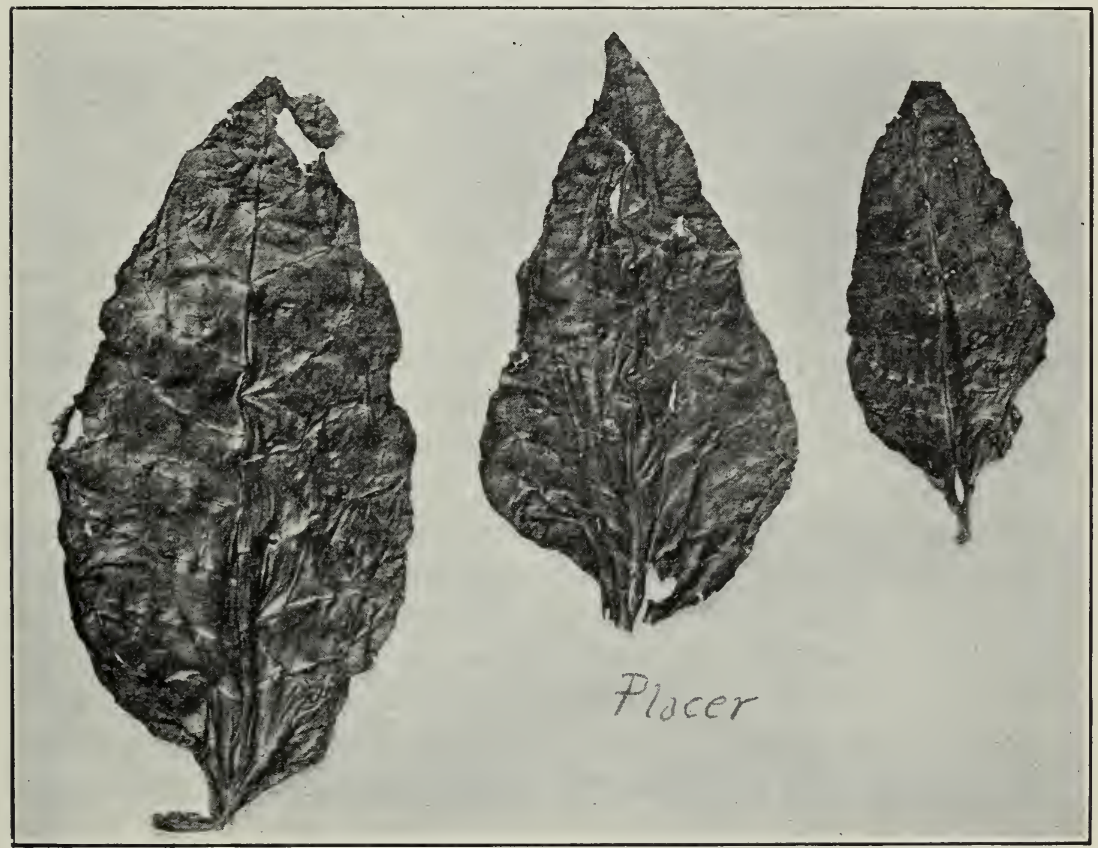

Fig. 6.-A good quality of hydrid leaf grown in Placer County, California.

Joaquin, Stanislaus, Fresno, Tulare, and other valley counties. Fair grades of tobacco have been grown in San Diego, San Benito, Los Angeles, Santa Cruz, and Contra Costa counties. An exceedingly good grade of leaf has been grown and cured in Napa County. The counties noted exhibit a considerable range of climate, yet fairly satisfactory results have been obtained in each case. The adaptability of the tobacco plant to various climates as here seen is very marked. However, the tobacco plant is very sensitive to sharp temperature changes between day and night. Such changes are very marked in our great valleys and the condition is undesirable. In the foothill 
sections bordering these valleys such temperature changes are not so marked and the conditions are to that extent more favorable. Regions where the heat of the day and the cold of the night are modified by the influence of the ocean offer the best conditions in this respect.

It may be said that the conditions prevailing in the great valleys are conducive to rank growth of the plants and a not wholly satisfactory leaf. These conditions make the work of curing much more difficult than when more moderate heat conditions prevail. Further, because of its rather soft, fleshy character the leaf may sunburn. This danger is more imminent as the leaf approaches maturity and greater change is going on in the tissue. In sections where some fog occurs, where there is some precipitation of dew at night, and yet where there is ample sunlight in the middle of the day, the climatic conditions more nearly meet the needs of the tobacco plants. The restrictions of climatic conditions are plainly shown in the tobacco plantings in various parts of this state. The quality of leaf, Samsoon and Dubaka and certain crosses between these (figs. 2, 3, 5), grown in the lower Napa valley where the favorable climatic conditions mentioned above prevail, is particularly fine. The aroma and bouquet while quite marked are not harsh nor strong. Sun curing is comparatively easy and the danger of sunburn is at a minimum.

Enough is now known to prove that the climatic conditions best suited to tobacco are found where the ocean influences are plainly felt. Yet it must not be inferred that the big valleys of the state are worthless for this crop. The fair product coming from them and especially from their foothills is proof that Turkish tobacco can be successfully grown in them. The sensitiveness of the tobacco plant to its environment and its adherence to type under given conditions make it especially easy for the grower to develop varieties suited to the climatic conditions of his own ranch. The observation regarding the influence of the ocean is in line with the experience of the Turkish tobacco sections of southeastern Europe and Asia Minor where some atmospheric humidity is the rule. Garner states: "In the portion of southern Macedonia around the port of Cavalla and other nearby towns and in the Smyrna, Trebizond and Samsoun districts of Asia Minor are grown the finest cigarette tobaccos in the world." ${ }_{5}$ It is worthy of note that the climates of the districts mentioned are modified by the influences of sea and

${ }^{5}$ Garner, W. W., Physiologist in charge of tobacco investigations, Bureau of Plant Industry, United States Department of Agriculture, article on Tobacco in Encyclopedia Americana, vol. 26, pp. 658-665. 
fog. These regions closely approximate the climatic conditions found in the small coastal valleys of California. From the evidence in hand there are undoubtedly very large areas in the big valleys where a fair grade of leaf can be produced and also much territory in smaller valleys where a most excellent product can be and is being turned out.

\section{SOILS}

A very wide range of soils can be successfully used for growing Turkish tobacco. Good crops have been noted on even such recalcitrant soils as the adobes. Because of the difficulty of properly working adobe soils and the coarseness of the leaf produced on them, the adobes should in most cases be avoided. A further objection to adobe soils is found in the difficulty experienced at transplanting time. It is very difficult to set the young and tender tobacco plants in the adobes and a poor stand frequently results. The plant, however, makes a wonderfully strong growth when once it has taken hold, provided the moisture content of the soil has been kept at the best by good cultural methods. Indeed the objection is often made to the adobe soils that the tobacco plant makes too rank a growth on them.

In order with the adobes come the clay loams. These, too, are hard to work to a fine tilth but when so worked are excellent for Turkish tobacco, giving good yields of an excellent leaf provided the climatic conditions are right. With these clay loam soils careful methods of preparation are necessary to secure the best results.

The loams on the whole may be considered as good soils for this crop. They are usually fairly easy to work down to the necessary fineness, are retentive of moisture, and are usually well supplied with the elements necessary for plant growth. The yield of leaf on the loams is usually excellent and the quality is good.

Sandy loams are usually very easy to work and their ability to retain moisture is excellent. The quality of leaf produced on them is very good, of fine aroma and satisfactory color. The yield is not so great ordinarily as on the previously mentioned soils.

The very sandy soils are light producers, easy to work but poorly retentive of moisture. A leaf of very fine quality is grown on soils of this type and though a light tonnage may be expected on the whole they are to be classed as thoroughly good soils for Turkish tobacco.

The silts which have a tendency to run together and puddle are, if tilth can be maintained, fairly satisfactory for this crop. 
Their variability of structure and character make them hard soils to manage and Turkish tobacco crops on such soils are apt to show much variation in style of leaf, and hence are difficult to harvest properly. Nevertheless good tonnages have been reported on the silt soils of the great valleys of the state.

The most satisfactory soil for Turkish tobaceo is a sandy loam with a considerable admixture of wash gravel and broken rock containing a good quantity of lime. Such soils may be low in their nitrogen content but this is an advantage so far as the tobacco plant is concerned. Turkish tobaceo grown on such soils would normally be of high quality with excellent leaves which, when properly cured, develop a fine aroma and bouquet. These soils would be considered of rather low agricultural value for other field crops or for orchard purposes. Of this type are the best soils for tobacco production in the Levant, Macedonia, Greece, and other countries. Such soils are to be found in our Sierra foothills and on the valley edges of the coast range of mountains. They at present maintain a meager agriculture but with intelligent care on the part of the grower could be made to produce remunerative crops of Turkish tobacco. It should be noted that the main plantings of tobacco have so far been made mostly under the climatic conditions of our big valleys and on comparatively heavy soils. The result has been a sacrifice of quality in favor of quantity.

It will be observed that Turkish tobaceo is very adaptable to various soils and that so far as this item is concerned can be grown over a wide range of territory. But its character is very sensitive to varying soil conditions and when grown on one type of soil produces a leaf that may differ strongly from the leaf grown on another. The variations will show in the size and texture of the leaf, in the coarseness or fineness of the midrib, in aroma, and in burning qualities.

It is therefore uncertain what the character of the leaf will be on a given soil until the crop has been grown, harvested and cured. Commercial plantings that have been under observation show that a given soil will, with occasional rests and rotations, develop uniformly a characteristic type of leaf provided a rational system of seed selection has been followed.

\section{PREPARATION OF THE LAND}

Turkish tobacco growing is a highly specialized form of agriculture and requires careful methods of work at all stages. This is as necessary in the matter of land preparation as in all the other operations 
together. The soil should be well supplied with decaying organic matter. A good top dressing of stable, cow yard, or sheep manure or of chicken droppings should be given the land in September before the first rains. Lacking these organic manures a good summer cover crop should be grown on the intended tobacco field. After the first rains the field should be plowed deep, turning under the manure dressing or the cover crop so that the material is well worked into the soil. An old alfalfa field that has been pastured for several seasons can be advantageously used, provided the alfalfa has been thoroughly killed out in the plowing process. Such a field usually is well supplied with organic matter at and close to the surface. The plowing must be well done and no "cut and cover" work should be tolerated. It should always be borne in mind that good careful work in preparation saves much labor in working the land when the crop is in.

Following this first plowing the land should be allowed to lie unworked for from six weeks to two months. At the end of this period the land should be gone over with a weed knife and such weeds as have appeared destroyed. If the field is an old alfalfa patch a good heavy hoe should be used to destroy such of the alfalfa plants as were not killed by the original plowing. It should be borne in mind that the more weeds and foul growths that are destroyed at this time the easier will be the work of keeping the field clean when the tobacco plants are set and growing. Again the field should be allowed to remain undisturbed and unworked until spring. At this time when danger of frost is about over the field should be put in a state of fine tilth by either plowing to a depth of about four inches and then lightly harrowing it or by going over it with a dise cultivator two ways. Treatment such as this should put the land in excellent condition. Of course the treatment of the soil will have to vary from the above ideal with the varying seasonal climatic conditions but the planter should come as near to it as possible. Not only does such careful work greatly reduce the labor of weed control but it increases the moisture retention possibilities of the soil. This latter item is one of very considerable importance as the tobacco plant is a great user of water and the transpiration of water vapor through the leaves is very considerable.

The field then being in a state of good tilth, low back-furrows should be run about four feet apart north and south the length of the field. A light harrow should be run over these back-furrows lengthwise. This should leave the back-furrowed portion of the field slightly higher than the rest and on this raised portion or low 
ridge the young plants should be set about two feet apart. This arrangement allows easy cultivation between the rows, and, if irrigation is practiced, the ridged condition in a measure protects the tobacco plants against direct contact with the water.

The width between the plants in the rows will in a measure have to be determined by the character of the soil. The general rule that the richer the soil the closer should be the plants in the row holds good.

\section{CULTIVATION AND IRRIGATION}

The careful preparation of the land makes the soil retentive of moisture. The great expanse of leaf surface presented in a field of Turkish tobacco that is growing well means a very considerable transpiration of water vapor and so every effort must be made to avoid further loss of soil moisture through evaporation (fig. 1). The field should be gone over with a light cultivator at rather frequent intervals. This keeps the soil in good tilth, destroys weeds, and thus overcomes transpiration of water vapor through the weed leaves. The space between the plants in the row should be gone over with a hoe occasionally to kill out weeds that may have started there. By this careful work a better chance is given the tobacco roots to develop and to use the nutrient elements of the soil. The tobacco plant sends out its main feeding roots laterally and fairly close to the surface, hence the optimum of soil moisture conditions must be maintained in that region. This closeness to the surface of the feeding roots further emphasizes the necessity of shallow, light cultivation and hoeing. Serious setbacks will result if these roots are destroyed.

In occasional cases, irrigation may become necessary, though it is to be avoided if possible. An index of the possible necessity of irrigation is to be found in the condition of the plants themselves. In the early morning the leaves will be upright and turgid owing to the fact that there will have been but little transpiration of water vapor during the night. If during the forenoon, say up to ten 0 'clock, the leaves wilt it is fairly certain there is not enough moisture in the soil and irrigation should be resorted to. On the other hand if wilting does not occur till well on in the afternoon the soil moisture condition may be considered good. Irrigation of tobacco plants should not be done unless there is a positive need of water. Care must be exercised to keep the water from coming in contact with the plant and it should be applied sparingly, as an excess of water is liable to cause root rot and other troubles. Further, if the plants get too much water they will become spindling and weedy; the leaves will become very light colored and thin, with very poor aroma and 
flavor (fig. 7), and will develop an over-coarse mid-rib. In short a leaf of poor quality will result from the improper and excessive use of water. To properly apply irrigation water a shallow furrow should be turned in the center of the rows. A small head of water should be run down this furrow, care being taken that the water does not escape from the furrow and form puddles about the plants. In

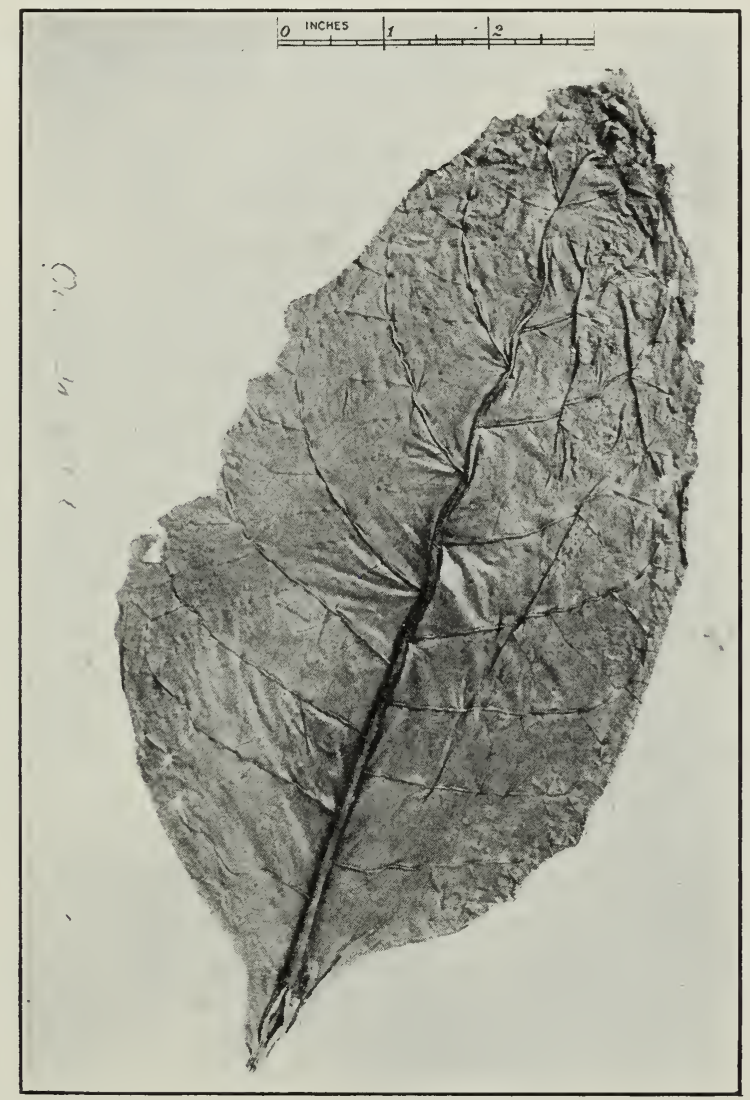

Fig. 7.-Over-irrigated. Note thinness of leaf and coarse mid-rib.

the well prepared field, water should seep laterally and downward fairly rapidly. A good supply of water can thus be evenly distributed through the field. As soon as it is possible to get on the ground after irrigation, the cultivators should be run over the land so that no baking or cracking will occur. Also the interspaces, where the cultivator has not broken the ground, should be well hoed. Water conservation in the soil must be accomplished if the best results with the plants are to be obtained. 


\section{THE SEED BED}

Great care must be exercised in preparing the seed bed for starting the plants later to be transplanted to the fields. The soil of the bed should be a light sandy loam well worked several times so that it will be in a fine state of tilth. As near the middle of March as weather conditions permit the ground to be used as a seed bed should be trenched to a depth of about fourteen inches and to a width of some four feet (fig. 8). For convenience the bed should be made about ten feet long. Fresh stable manure should be placed in the trench so that when it is well tamped down the manure layer will be six or seven inches thick. Fill in the well worked bed soil above the manure layer. Then build sides and ends of ten inch boards to enclose the bed, filling in soil so that the top of the bed will be about two or three inches higher than the surrounding land. Provide a frame of wood strips that will easily fit over the bed sides and ends and cover this with light sheeting. This cover should be provided with cross pieces so that the cloth will not sag down to the plants when they are growing. The manure layer furnishes, through the process of decay, a considerable amount of bottom heat and when temperature conditions demand it, the cover can be kept in place and the whole interior kept warm and in good condition to foster growth.

Some planters sterilize the bed soil by burning quantities of straw over it, thus destroying many weed seeds. In the tobacco sections of the eastern states this method of seed destroying is common. In our observations, firing the bed soil is not the best practice as it burns out the organic matter in the soil. This makes the earth puddle and crust easily, which is a condition that should be avoided. In the dark tobacco, Burley and Sumatra seed sections, burning the seed beds and also steaming them is done to destroy weed seed. These processes are not necessary under our California conditions provided the seed bed soil has been under preparation for some time before seeding is done and all weed growth has started and been destroyed.

The preparation of the seed bed being completed and the last light raking done, the planter should be prepared to do his seeding. The tobacco seed is extremely small, ranging not more than one millimeter in length, and one rounded teaspoonful is ample to seed a bed of the size above described and this in turn will, if germination is good, furnish between five and six thousand plants or enough 
to set one acre of land. The seed is broadcasted in the bed soil. Some growers mix the seed with four or five times the bulk of cornmeal which helps to an even distribution of the seed. There is a danger in this practice as under the bed conditions of heat and moisture molds are likely to develop and seriously injure the young plants. In the eastern tobacco growing sections and in a few isolated cases in California powdered gypsum has been used instead of cornmeal at the rate of four times as much gypsum as seed by

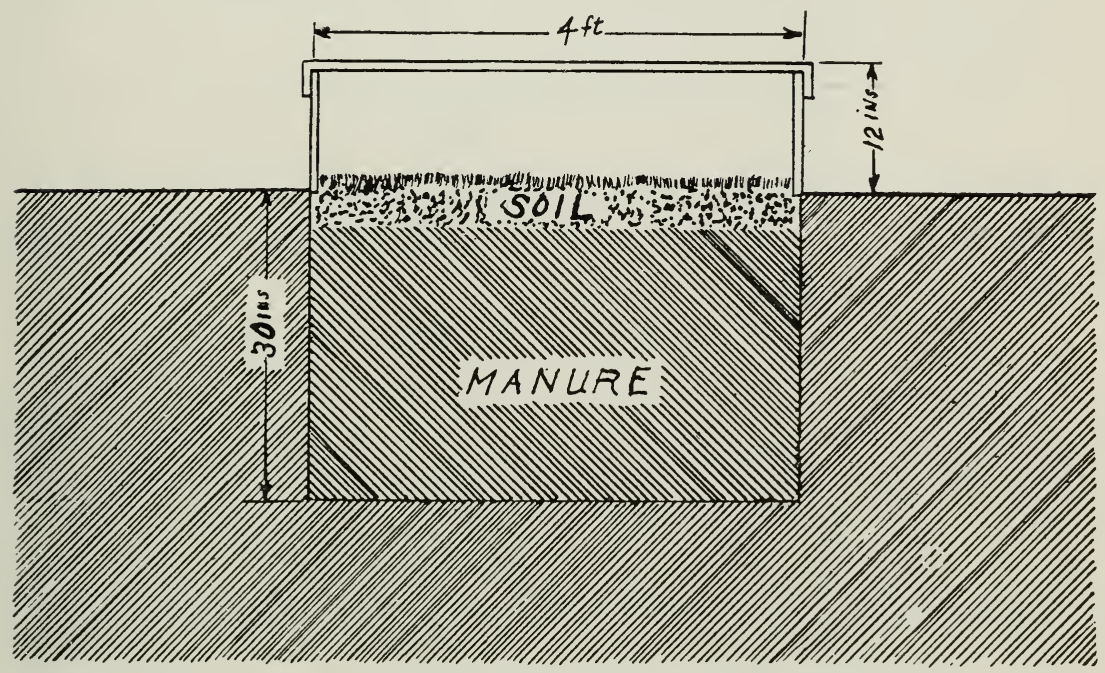

\section{HOT BED, CROSS SECTION \\ Scale, ${ }^{\prime \prime}=1$ foot}

Fig. 8.-Hot bed showing detail of construction.

volume. This medium for carrying the seed is very satisfactory as its color affords a ready index as to the evenness of seed distribution, and though the amount of gypsum is minute it seems to have a stimulating effect on the seedlings. After the seed has been broadcasted it should be lightly brushed in and the soil somewhat compacted with a board. The bed should be sprinkled with water, not drenched, and the moisture supply should be kept at the surface until the plants start.

Much care must be exercised at this time both in the matter of watering and in that of ventilating the bed. With too much humidity and warmth the young plants may be killed in great numbers by "damping off," a fungous disease that attacks them at or about the ground surface. On the other hand, if the bed is overventilated and kept too cool germination may be seriously delayed. Some 
growers as a precautionary measure dust the beds lightly with finely powdered sulfur and no doubt this to some degree overcomes danger of "damping off."

The germination of tobacco seed is usually slow and in some cases the seed may not start at all. It is decidedly a good plan to have the seed tested for germination. ${ }^{6}$

In three trial tests made to determine the germination power of Turkish tobacco seed grown in California and purchased in the open market the results were as follows: (The length of test with each lot was 15 days.)

$\begin{array}{ll}\text { Lot } 1 & \text { Germination } 82.5 \text { per cent } \\ \text { Lot } 2 & 84.0 \\ \text { Lot } 3 & 84.5\end{array}$

These may be considered good tests and such seed can be safely used.

\section{TRANSPLANTING}

All having gone well with the seed bed and the young plants having attained a height of from two to four inches, transplanting to the field should begin. Ordinarily transplanting occurs from the middle to the last of April though the exact time will depend on the advance of the season. A careful study of the work of many growers shows that a two-to-four-inch seedling is preferred as it seems to take hold better than the larger plants when planted out in the field. The seed bed should be loosened up carefully with a spading fork and the plants gently drawn and bunched, roots to roots. This work should be done preferably on a cloudy day, and in any case the young drawn plants should be kept moist and in the shade from the time they are drawn until they are planted in the field. If cloudy weather does not occur at planting time then the work should be done in the late afternoon and evening.

From the seed beds, the plants are taken to the field in boxes covered with wet sacks. Planting may be done by hand or with a horse drawn planter. Greater success has been reported from the eastern tobacco plantations when mechanical planters were used than when the work was done by hand. If the work is done by hand the operator should be provided with a wooden dibble or with a narrow bladed trowel. With these he makes the hole for the young plant and then sets it, taking care that the roots are worked downward and that the soil is well compacted about the crovn of the plant.

6This work is done at the seed testing laboratory, State Department of Agriculture, Sacramento, California. 
The planters should be followed immediately by a tank wagon of some sort, and each plant should receive about a quart of water to insure a fair compacting of the earth about the roots and to furnish the young plant with an ample supply of water during the trying time of starting new roots.

If planting machines are used, the labor of this operation is greatly reduced and a more even stand can be expected. Whether the mechanical planter is used or the plants are put out by hand, the ridge made in preparation of the land should be followed carefully. A man with a hoe should follow the planter, adjust the covering of the small plants, and cover over wet places so that no baking of the soil may occur.

The young Turkish tobacco plants have good vitality and should not show the shock incident to transplanting for more than a day or two.

\section{FIELD TREATMENT AND PICKING}

From the time the plants have begun to grow in the field, constant care and attention must be given them. Shallow cultivation must be practiced at frequent intervals to destroy weeds and thus prevent too rapid water transpiration from the soil and so avoid the necessity of irrigation. Care must be taken to pinch out the suckers at the leaf bases as they rob the plant of nutriment and so detract from the value of the product. For this purpose the patch must be gone over every few days. While removing suckers, a lookout for tobacco worms must be maintained and these voracious pests destroyed when found. Weeds must be hoed out and in fact the best cultural conditions maintained. The farmer should have the best product as his ideal and he may be sure that the plants will respond to good care. Care must be exercised not to bruise or break leaves as such leaves make a low grade product.

The question as to whether blossoms should be removed can, from the evidence in hand, be answered in the affirmative. By such removal or topping as soon as the panicle begins to form, the strength and vitality of the plant goes into leaf production and better quality and more uniform size of leaves is the result. Of course the blossoms of seed bearing bearing plants will have to be left as explained on pages $644-648$.

If all has gone well, in from forty-five to fifty days after transplanting, the lowest leaves called 'refuse' will show a slight yellowing at the tip and a slight greenish yellow spotting which indicates ripening. They are then ready to be picked. Usually these 'refuse' leaves are ignored, though occasionally they are cured and used in 
making insecticides and low grade tobacco products. The tobacco leaves ripen in order from the lowest to those near the blossom panicle and the pickers must go over the field at frequent intervals so that the leaves do not get over-ripe. Picking of leaves must be done in the late afternoon and early evening after the temperature has fallen but before the dew begins to fall. This work may also be done in the morning after the dew has disappeared but before the heat of the day is on. After the picking of the refuse comes the taking off of the 'sand' leaves, the next whorl or two above (fig. 4). These leaves receive their name from the fact that they carry some dust and grit owing to their nearness to the ground. The next series above, usually of two whorls, is known as 'basma.' Then comes the series, usually again of two whorls, known as 'gubec' (dubec, dubeque, djubec). These leaves when properly taken and correctly cured are of fine quality and much sought for in the trade. Next in order comes the smaller leaves known as 'Ooch-alte' and 'Ooch.' These highest, smallest leaves may be not more than one inch long and still be of the best quality. There is no arbitrary rule that can be set down to govern the picker in his choice of leaves for grades. Expertness in this comes only with practice. Leaves of a given grade should be kept together in the picking. For instance the picker taking basma leaves should not mix them with gubec leaves even though the latter may be in condition to pick. These should be taken in a second picking. The leaves should be handled with care to avoid breakage as much as possible; they should be carried to light packing cases (fig. 1) and placed in these in an orderly manner so they may be easily removed without damage. If the removal of the blossoms or topping has been practiced the difference in size of leaves will not be marked.

\section{FIRST OPERATIONS IN CURING}

The loosely filled packing cases are taken to the barn or shed, where stringing is done. This process consists of threading the leaves on linen or cotton strings with a spear headed needle. The petiole of the leaf is pierced with the needle about three-quarters of an inch from the end and the leaves drawn down on the string. The process may be likened to stringing beads. Some care must be exercised so as not to split the petiole or the leaf. The strings should be eight feet long and in stringing twelve inches should be left clear for tying purposes at each end. The leaves on a string should all face the same way and should be so spaced as not to touch when the string is stretched and the leaves hanging down. A quarter of an inch 
apart has been found to be a satisfactory spacing. Poles seven feet long and from an inch to an inch and a quarter in diameter should be provided in quantity. The giant reed (Arundo donax) is used whenever obtainable as it makes strong yet light poles (frontispiece). When the string is filled for some six feet of its length the free ends are tied to either end of the pole, the string being stretched so that sagging down of the leaves will be reduced to a minimum when the loaded poles are racked. The racks both in the barn or shed and those used out of doors are made so that the free ends

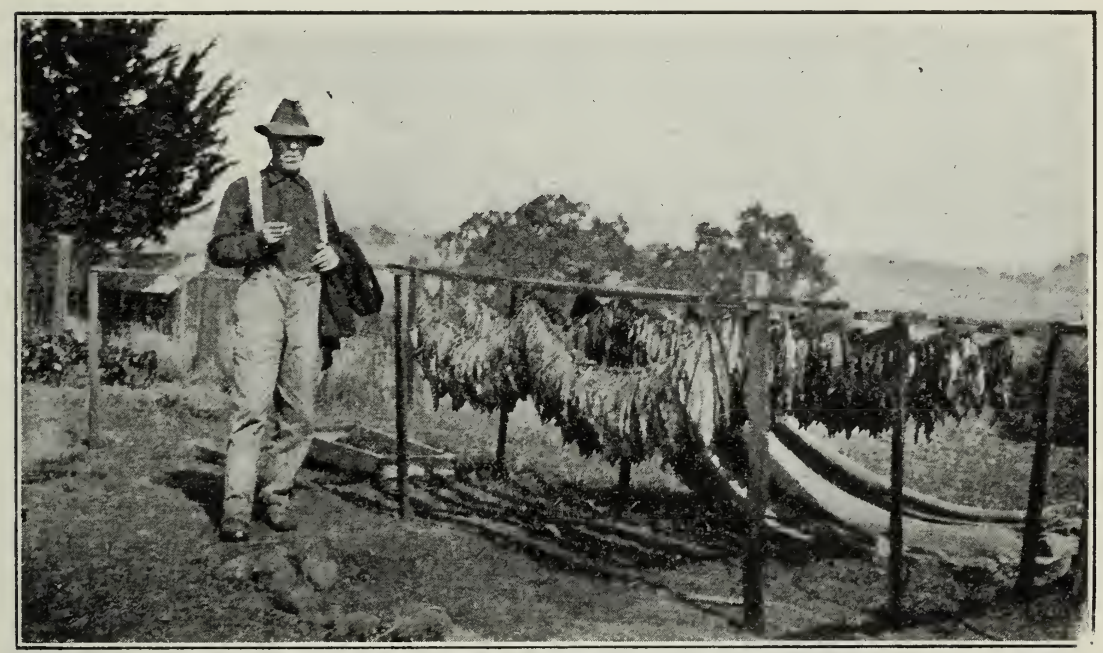

Fig. 9.-Small sun-curing rack showing burlap covers removed.

of the poles will engage them and the leaves on the strings hang down. A string should be tied in such a way as to relieve the sag at the pole center. The poles with their leaf-laden strings are then racked in a shed or barn with small free air spaces between the strings and left in a closed room for from twenty-four to fortyeight hours for their first wilting (figs. 10-11). There must be good ventilation in the shed or barn while this process is going on so that the air about the leaves will not became excessively humid. Too quick wilting or on the other hand too much moisture at this time will detract from the quality of the leaf. The end of the first process will be indicated by the leaves turning a greenish yellow to lemon yellow in color.

After wilting, the strings of leaves on poles are removed to a larger room or barn and allowed to remain there for twenty-four hours or until all the moisture has disappeared. They are then 
removed to outside racks (frontispiece and fig. 9). These racks are best placed over stony ground. If such ground is not available the best plan is to haul rock, either wash gravel of fair size, or broken rock, to the rack site so that the curing leaf may hang over stony ground. As even a temperature as possible should be kept about the leaves. This is promoted by the rocky floor which takes in heat during the day and slowly gives it up at night. The poles of leaves can be racked overnight in the barn and this perhaps is better than leaving them outdoors over the rock floors

Covers of burlap somewhat larger than the area covered by the racks should be provided (fig. 9). These may be used to shade the racks of leaves if the sun heat becomes excessive, say about $80^{\circ} \mathrm{F}$. The burlap covers should be placed over the racks if fog occurs and should certainly be in position shortly before sunset. They should hang down at the ends and sides of the racks as far as the leaf tips do. They are necessary in properly starting the curing of the leaf, as they tend to retain radiated heat from the rock bottom and exclude fog or excess of dew. They are also quite indispensible as shade producers if the sun's heat becomes excessive. It may be necessary to take them off or put them on several times a day-to get the best results.

\section{CURING BARNS}

For convenience and economy in handling the tobacco during the stages prior to fermentation and grading, especially designed barns are desirable. Figures 10 and 11 are suggestive of how such barns should be constructed. Figure 10 shows the exterior of the barn in outline. In this figure $G$ is a double door affording ingress for wagons while a similar door is placed at the rear allowing egress; $\mathrm{H}$ is a double window large enough to allow the passing in of racks of strings of tobacco over tracks like those used in prune curing yards and $\mathrm{C}$ is the room for preliminary wilting as described on page 661 .

In figure 11 is the same barn with the front removed to show the interior arrangement. In this figure A indicates the door or entrance; $\mathrm{B}$, a sorting platform; C, the wilting room; D, trusses to support the garlands (fig. 17) ; E, controllable ventilators; and F-F, openings for ventilation. In a barn of this type the rapidity of curing can be controlled as well as the humidity, by a careful use of the ventilators.

This barn also obviates the necessity of curing the tobacco outside at night. It is extremely difficult to give the tobacco even temperature day and night by the burlap covering method. 
In the use of this barn, all the doors and openings are left open until about 4 P. M. As the temperature outside begins to fall, the tobacco in the process of sun curing outside during the day is rolled into the barn over the tracks and the barn shut tight. Heat collected in the barn during the day will be preserved and a nearly uniform temperature between day and night insured.

This style of a barn was developed by Alfred Aram, president of The Associated Tobacco Growers Inc. of California and has been successfully used in this state. It is known as the Pacific Type Cure House.

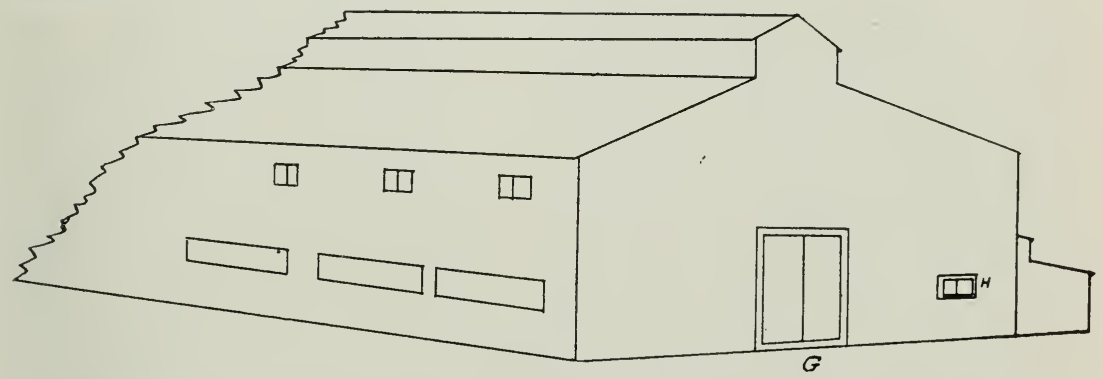

Fig. 10.-Outline of the Pacific Type Cure House. For detail see text.

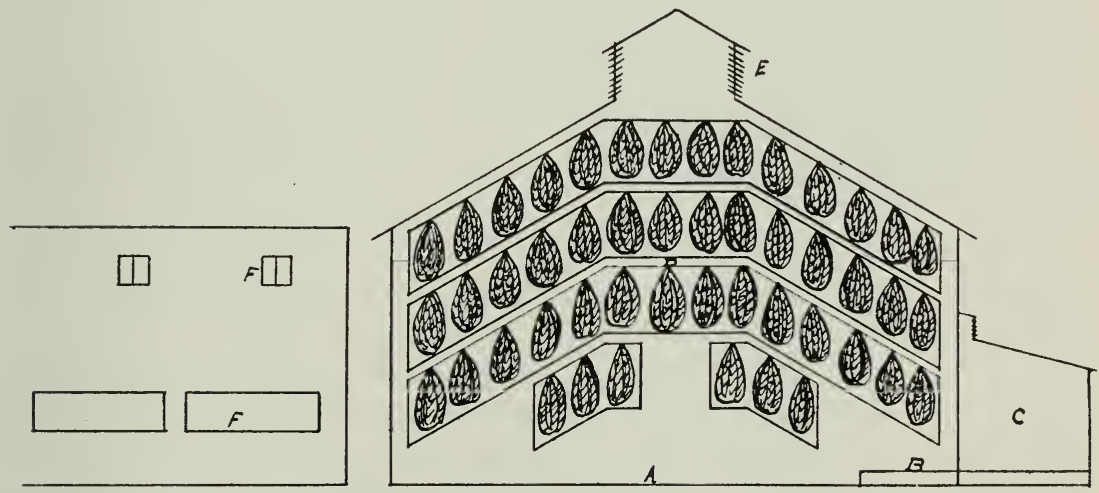

Fig. 11.-Section of a Pacific Type Cure House. For detail see text.

\section{SOME SUGGESTIONS}

It will be seen that Turkish tobacco raising is a highly specialized industry requiring the greatest attention to detail at all times. The grower must exercise judgment and care from the choice of seed to the end of the preliminary curing. Of course he could carry the leaf through the fermentation and grading but on the whole it would be poor policy to do so. The manufacturers demand a uniform pro- 
duct and if each grower cures his leaf to the selling stage such uniformity cannot be obtained. There would be about as many variations in the cured product as there were individuals engaged in the work. Standardization is well understood by our California farmers and this can be accomplished by the growers only by well considered and well executed coöperation. Without this sort of coöperation the individual will find himself at the mercy of a not too friendly market and his venture will end in failure. Central curing, grading, and aging barns should be provided. They should not be privately owned and operated but should be coöperatively the property of the growers. Men should be employed to manage them who are experts in the various manipulations the leaf must undergo so that the final result will be proper curing, good quality, and uniform grading. Lack of uniformity of curing (fig. 12) will in itself tend to degrade the product and reduce the price. The coöperative idea in handling agricultural products is not a new one to the farmers of this state. The time is not so far back when butter was manufactured on the farm and each purchase the consumer made might be considered an experiment. Sometimes the product pleased and sometimes it was a disappointment. Then came the day of the creameries, mostly operated coöperatively, and the result was improvement in the quality and uniformity in the character of the butter.

Standardization is well understood by our fruitmen and no successful orchardist would admit any desirability whatever in the hit or miss jumble of former days. The business could not stand the strain.

The grower of Turkish tobacco should profit by the lessons taught in other lines of agriculture and be a coöperator first, last, and always. He should, through coöperation, be in a position to put the manufactured article on the market provided he cannot get a fairly remunerative price otherwise. He should remember that the honest buyer would prefer to buy where there are large lots of a uniform type than to search for this type through a large number of non-uniform lots of leaf. The business of curing and disposing of the crop can be expected to remain in the unsatisfactory position it has so far occupied unless this general idea of coöperation is developed and maintained. 


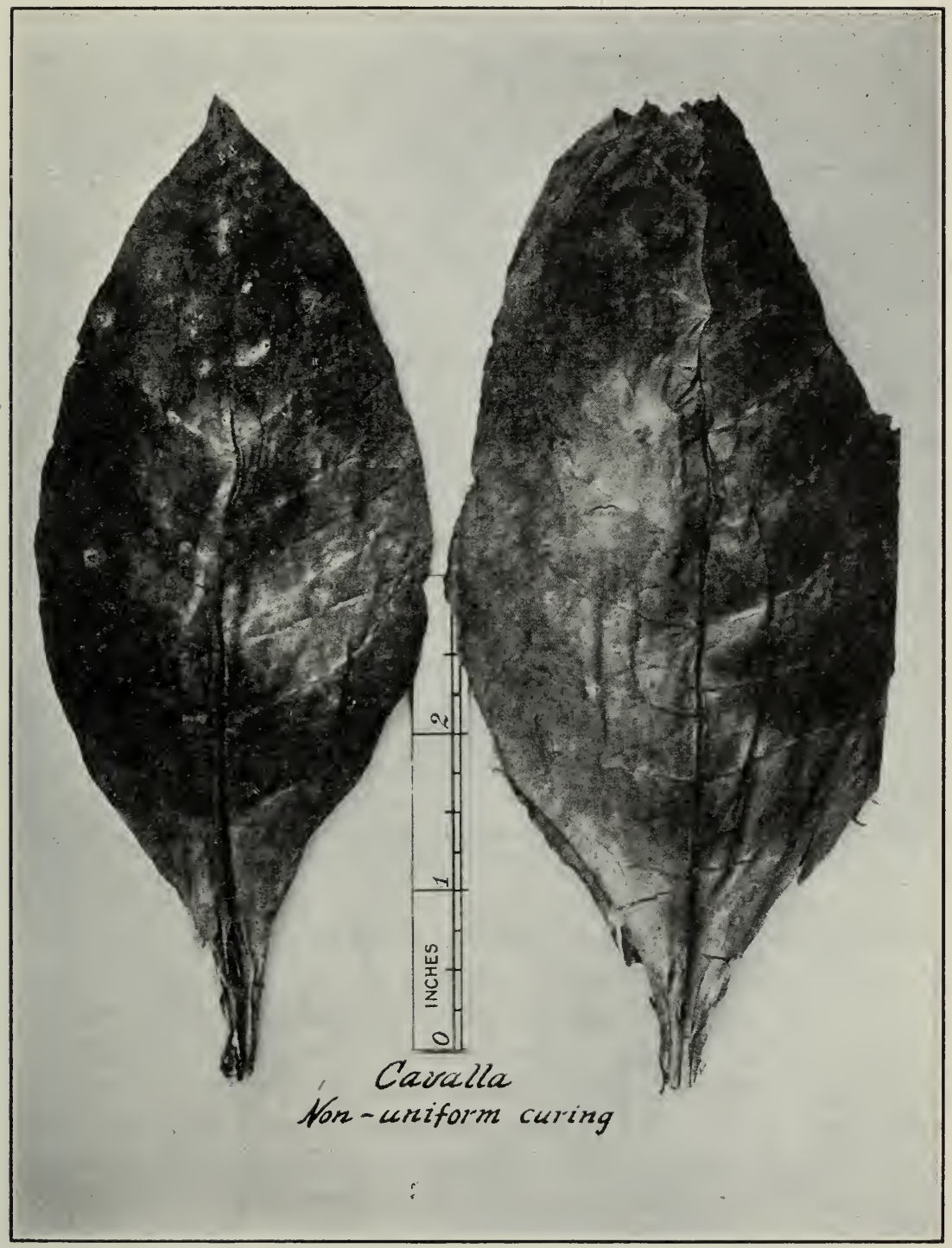

Fig. 12.-Non-uniform curing. Note variations in shading. This condition eaused a reduction in price of the product. 


\section{FERMENTATION, GRADING, AND MARKETING}

\section{Contribution of Alfred Aram, President, Associated Tobacco Growers Inc., of California}

The success of the final fermentation and uniform grading determines to a great extent the value of the finished product. Under no condition, however, will good fermentation overcome the results of mistakes during the growing and sun curing. To ferment Turkish tobacco special equipment and expert supervision is essential. This makes it both inadvisable and expensive for the farmer to cure his own crop. Also, the work of grading the tobacco to uniform grades acceptable to the manufacturer is very important and the fermentation and grading are best done at the same time and place. It is evident that if each farmer were to undertake to grade his crop there could be no uniform grades. The necessity of uniform grades and their relation to marketability and price is too well understood by the California farmers to need further comment.

\section{METHODS OF FERMENTING TURKISH TYPE TOBACCO}

There are two methods of fermentation, 'bulk' fermentation, and 'bale' fermentation. The particular method to be followed can be determined only by experts who must carefully consider the quality, the condition, the intended use, weather conditions, and the preferences of the market.

Bulk fermentation.- In previous chapters we have seen that after the sun-cure the tobacco strings are hung in the barn in garlands of five strings (figs. 11-17). In the fall or early winter, damp weather will make the tobacco soft and pliable and it can then be handled without danger of breaking the leaves. The garlands are now taken down and delivered to the nearest receiving plant or warehouse equipped to ferment and grade the tobacco and bale it ready for shipment. For bulk fermentation the tobacco should not contain more than four per cent nor less than three per cent of moisture by weight. Not often does tobacco delivered in the fall contain less than the minimum moisture required. In most cases it is far in excess of the maximum four per cent. The first step in the warehouse is to bring the tobacco to the desired moisture content. This is done either by ventilation or the application of slow heat or both. A satisfactory method of testing the moisture content is to take a number of leaves from a number of garlands 
and weigh them. Then the leaves are thoroughly dried and weighed again. The loss in weight represents the weight of the moisture evaporated. The percentage can be arrived at by the formula $\frac{100 \mathrm{~A}}{\mathrm{~B}}=\mathrm{X}$ where $\mathrm{A}$ represents the loss in weight, $\mathrm{B}$ the weight before drying, and $\mathrm{X}$ the percentage of moisture content to be determined. After the tobacco is brought to the proper moisture content the bulk or pile is made in a room where humidity and temperature can be controlled. The bed is first laid on the clean board floor by putting trash (tobacco of no commercial value) or blankets about three inches high and covering a space $10 \times 10$ feet, the tobacco to be fermented is next laid on this bed in straight rows with the strings in straight lines and the leaves overlapping about one-half of their length. Since the strings are seven feet long and the fermenting pile ten feet long there will be three feet 'overage.' This is necessary as will be explained later. In making the pile and laying the strings the method shown in the diagrams is followed (fig. 13).
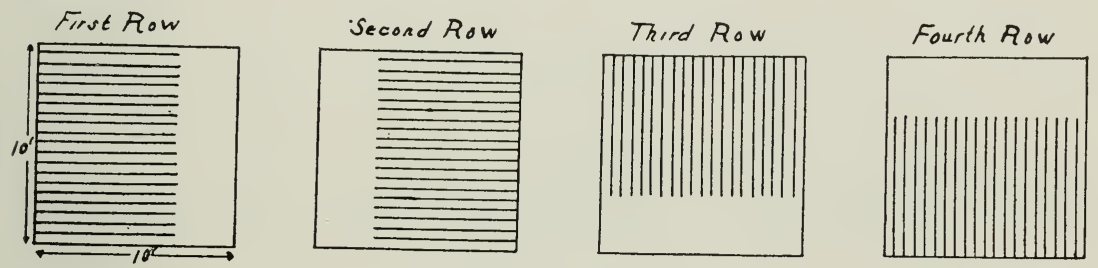

Fig. 13.-Arrangement of strings of tobacco for bulk fermentation. For detail see text.

All the stems in the first layer point in the same direction while the stems in the second layer point in the opposite direction. This method of alternating the direction of the stems and the 'overage' is carried out to the completion of the pile ten feet high. It will be seen that every fourth layer will have the same direction of stems and overage.

In building the pile or bulk, when it is five feet high a specially constructed thermometer is placed on the pile with the base at the center of the pile and the reading end projecting beyond the edge. The entire bulk is then covered with blankets or quilts provided for this purpose.

The pile is now left to 'heat up' to the desired degree but under no condition to exceed $120^{\circ} \mathrm{F}$. This first heating may require from eight to twenty-four hours according to a number of conditions. When the first heating has reached the desired point, the pile is 
torn down, the tobacco allowed to cool and bulked again for the second heating. It is obvious that the center is the warmest part of the bulk and the temperature decreases in the direction of the outer edges. Therefore in building the second pile from the first pile special care is necessary in order that the tobacco on or near the outer edges at the first pile will come near the center of the second pile. This is essential to insure the uniform fermentation of all the tobacco. This may be accomplished in several ways. The following method is satisfactory.

The pile is taken down from the top until approximately onefourth is taken off and laid to one side (fig. 14). This is represented in the following diagram as Section A. Then Section B is taken off and placed to the opposite side of the pile. Section C is placed on Section B and Section D on Section A. This leaves vacant the place occupied by the first pile. A new bed is made on the space occupied by the first pile and the second pile is constructed by placing all the various sections in the order of C. D. A. B.

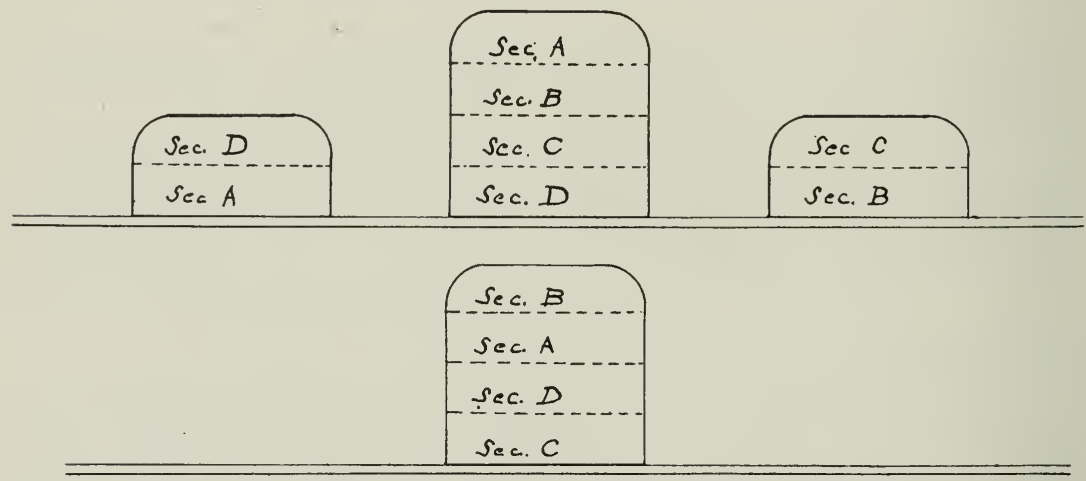

Fig. 14.-Piling for bulk fermentation. For detail see text.

It will be noted that Sections $B$ and $C$ were in the center of the first pile and received the maximum amount of fermentation while Sections $A$ and $D$ being at the top and bottom respectively received the minimum of fermentation. In the new pile, Sections A and D are placed at the center with $\mathrm{B}$ and $\mathrm{C}$ at the top and bottom respectively. In making up the second pile a system should be followed so as to insure, without confusion and mistakes, that the ends of the strings at the outer edge of the first pile will come inside of the overage of the second pile. This is necessary to give uniform fermentation to both ends of the strings. The method of alternating the ends of the strings in the overage from the first to the second 
pile may be made clear by the following diagram (fig. 15). This second pile is also allowed to heat to the predetermined point and taken down, and the operation is repeated as before until the tobacco has fermented to the required degree. No definite statement can be made as to the number of bulkings necessary. That is governed by several considerations and can be determined only in each individual case at the time.
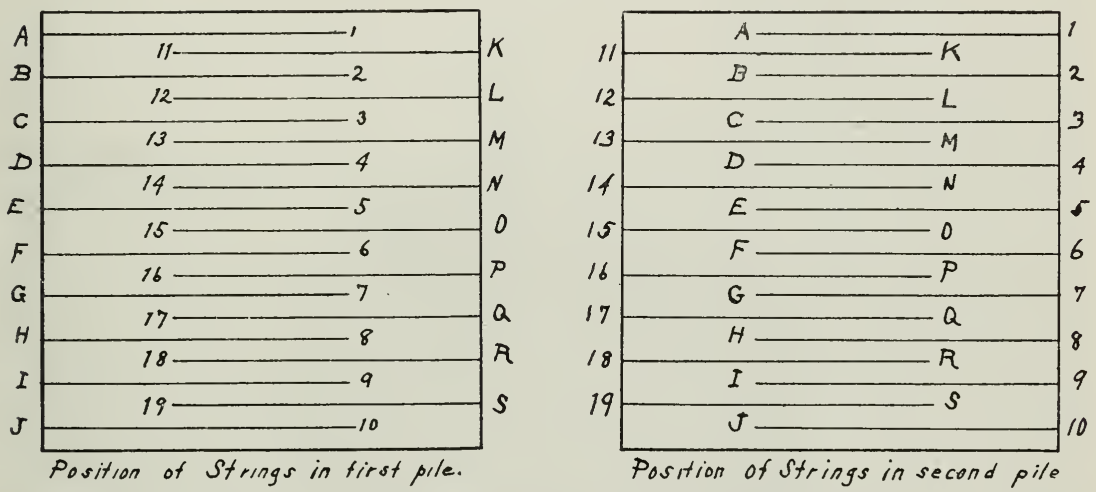

Fig. 15.-Method of alternating position of strings from first to second pile. For detail see text.

When the fermentation is complete, the tobacco is allowed to cool and then it is graded according to color, size, and smoking quality. This also can only be done under expert supervision with accurate knowledge of manufacturer's requirements, the needs of the market intended to be reached, and the types of cigarettes in which the tobacco is to be used. After grading, the tobacco is made into uniform bales of approximately 100 pounds each. It is essential that each bale should contain tobacco of similar color, quality, and size.

The baling is done by the use of collapsible boxes in which the tobacco strings are placed in uniform rows and in such a way that only stems will be exposed at the two opposite sides of the bale. The contents of the box is then subjected to pressure under screw presses and allowed to remain under pressure for a few hours. The pressure is then released, the box taken apart and the tobacco covered with burlap on four sides-the top, bottom, and the two ends, leaving the two sides formed by the stems exposed. These sides are laced as shown in figure 16. This method of baling makes it possible to examine the tobacco in the bale by loosening the lace one one side and after examination the lace can be drawn tight and the 
bale restored to its shape without opening the burlap covering. If the fermentation has been done properly, the tobacco should not heat again in the bales. However, it is advisable to shift the bales and change their position once in ten days during the months of April and May following.

Bale fermentation.- - In this method of fermentation the tobacco is graded upon the delivery at the warehouse, the moisture is fixed at not more than three per cent, and the material is baled as described under bulk fermentation. The bales are placed on shelves in a building where the tobacco is not subject to the variation of outside temperature. The bales are carefully inspected and their position shifted every ten days. Any bales developing more than the

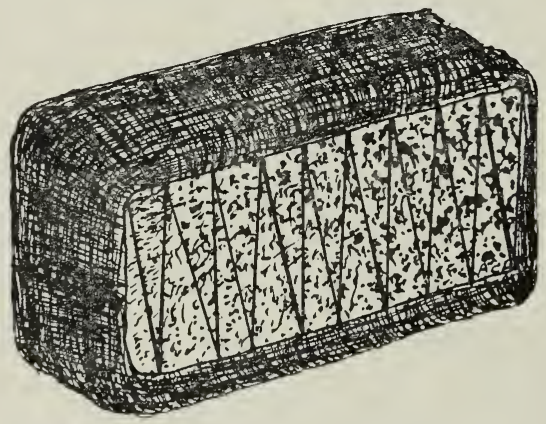

Fig. 16.-One hundred pound bale of tobacco showing side lacing.

required heat are loosened by opening the lace sides (fig. 16) and air is allowed to penetrate through. The shifting of the bales must continue until fermentation has progressed sufficiently so that no longer heat is generated to a degree to damage the tobacco. During the April and May following they must be examined again and any bales having a tendency to heat must be shifted every week or ten days. Excessive moisture content at the time of baling or overheating from failure to examine and shift the bales, will result in molding, which destroys the value of the tobacco for smoking purposes. The bale method of fermentation is a slow process and takes several months to complete but the results are satisfactory. Bulk fermentation is completed in a comparatively short time and it makes possible a degree of uniformity of the finished product rarely attainable by the bale method. Each has its enthusiastic advocates. The bulk method, however, should never be attempted except under proved expert supervision. It is more exacting and lack of constant vigilance or mistakes will result in serious damage to the tobacco. 


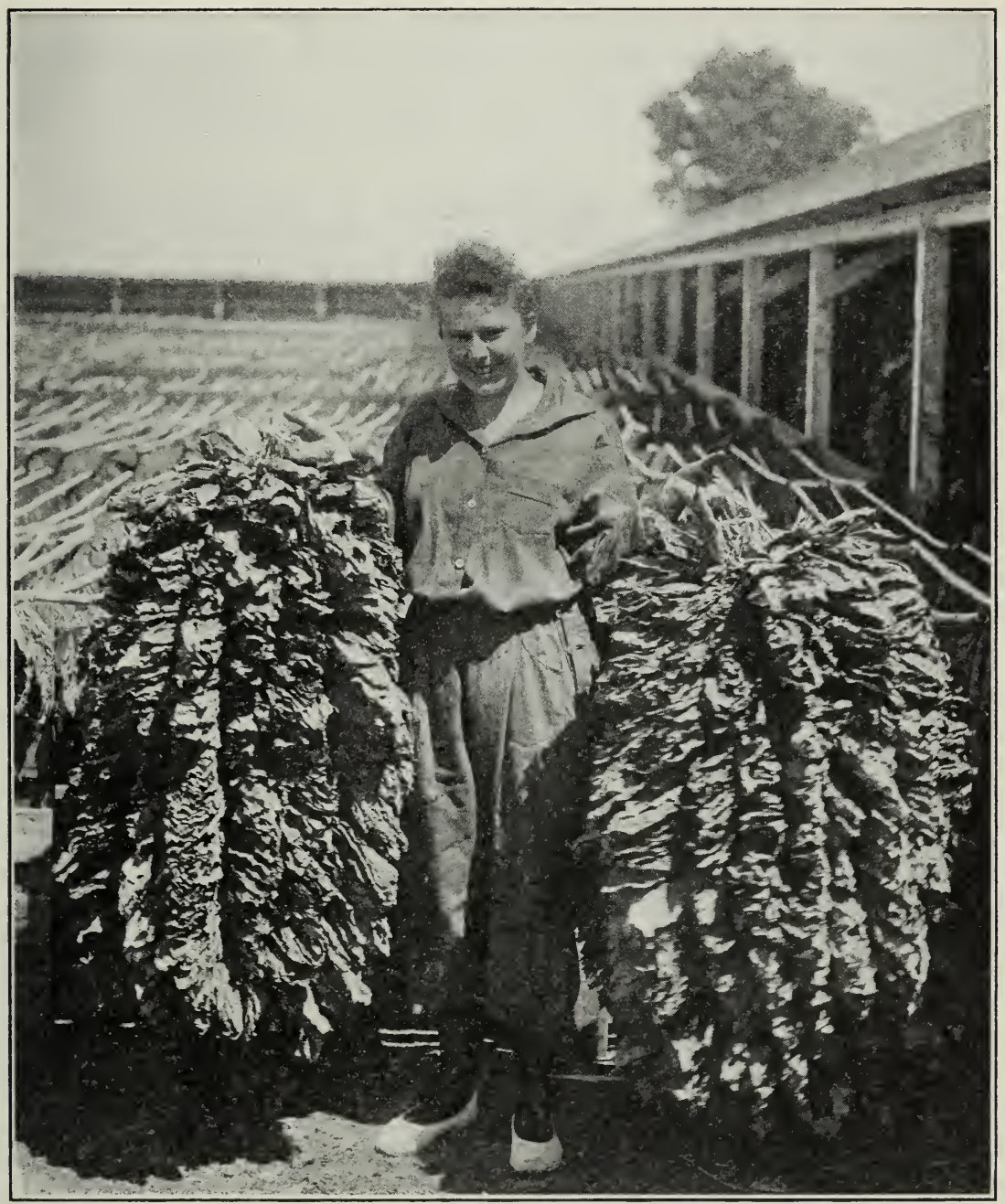

Fig. 17.-Garlanded strings of tobacco ready for cure house. 
The foregoing description of the various methods of fermentation is given for the purpose of acquainting the farmer with the character and importance of the work involved in making the crop a finished, marketable commodity. A detailed, scientific discussion of fermentation is beyond the scope of this paper and of no practical value to the farmer. Specialized training, practical experience, knowledge of the needs of the various markets and manufacturers, and special equipment are absolute requirements for this work.

\section{MARKETING TURKISH TOBACCO}

To determine the method of marketing best adopted to this crop, it is well to keep in mind that

(a) Prior to fermentation, Turkish tobacco is highly perishable. The work of fermentation can not be delayed later than the November following the harvest. Beyond that period the tobacco cannot be held, nor can it be shipped a distance of more than a day's journey.

(b) Until it is properly fermented, graded, and baled, tobacco is not a finished product acceptable to the manufacturer. It cannot enter the national or world market. The trade is confined to tobacco ready for the manufacturer.

It follows that farmers who must sell their crop before fermentation and grading have a very short time in which to dispose of it and can only sell to buyers who may be willing to buy the tobacco where it is. Under these conditions the farmer must accept whatever these local buyers may be willing to pay. The fact that leaf tobacco is a commodity enjoying a world-wide market and is bought and sold throughout the year in all countries is of no practical value to the farmer who must sell his tobacco prior to fermentation and grading. Only those who have properly fermented and graded tobacco to sell have access to the market in leaf tobacco. In the countries of the Levant, local receiving warehouses are owned and operated by brokers or branch offices of large manufacturers. The farmer sells his crop to these buyers soon after the tobacco is sun-cured. This system has not been satisfactory to the farmer. Its defects, from the farmer's standpoint, are obvious. The system has persisted in the Levant because social and economic conditions prevailing there have made it difficult if not impossible for the 
farmers to have their own finishing plants and to market their tobacco coöperatively.

The success of coöperative marketing in California suggests that the tobaceo growers of this state should own and operate the receiving warehouses in each district on the coöperative principle. That the tobaceo growers of the state realize this is indicated by the fact that there has been organized the "Associated Tobaceo Growers Inc." of California, a non-stock, non-profit, growers marketing association.

\section{PESTS}

Already a number of pests have appeared to vex the grower of tobacco in California. The greatest losses noted have been caused by jack rabbits. The tobacco plant with its very bitter, unpleasant tasting leaves would not seem to be very tempting to these animals vet they find the interior portion of the main stalk much to their liking. This portion of the growing plant is sweet and succulent and the jack rabbits gnaw away the bark and eat out the heart of the plant, thus causing its death. The writer has seen a field of tobacco so badly injured by jack rabbits that it was not worth harvesting. A good rabbit proof fence of meshed wire fencing and the conseientious use of the shotgun will adequately control this pest. Some success has been had with poisoned baits. The most efficient poison bait so far reported has been raisins with a minute crystal of strychnine worked into each one.

Ground squirrels are reported to have caused losses in many cases though not so great as those caused by jack rabbits. Before the field is planted, a vigorous campaign of destruction of squirrels should be carried on. Poisoned baits, raisins and strychnine, and poisoned grains should be used. Destruction by gasses should also be a part of the campaign. The State Department of Agriculture, Sacramento, California, will, through its Division of Rodent Control, aid in a practical way in such a campaign. The College of Agriculture of the University of California is also prepared to aid and assist in work of this sort.

Of insect pests, several kinds have proved so far to be somewhat troublesome. Grasshoppers have been reported as a menace, though the damage caused by them has been insignificant.

The common tomato worm and the tobaceo worm, the larvae of certain of the humming-bird moths known as the horned caterpillars (Protoparce sexta and Protoparce quinquemaculata) are probably the most troublesome insect pests in the tobacco fields. So far control has been obtained by destroying the individual worms when 
seen and by destroying the egg masses. The eggs are laid on the under sides of the larger leaves near the center and the number may run as high as thirty to each mass. The moths fly freely in the early evening and some growers report great success in light-trapping the pregnant females. The method used is to place ordinary lanterns in shallow pans having about an inch of oil coated water in them. These are put about in the field, and the moths, attracted by the lights, dash to them and fall into the oil-coated water. By using all three methods, the damage done by the larvae of the hummingbird moth may be reduced to the minimum.

The tobacco flea beetle (Epitrix sp.) is frequently troublesome in tobacco fields. It is a very minute, dark brown to black beetle which when seen under a fairly strong magnifying glass is found to be quite pilose. It can be readily recognized from its jumping movements which resemble those of a flea and from which it takes its name.

Cut-worms, the larvae of certain noctuid moths, occasionally do damage to, or even destroy, the young plants. Good cultural methods usually keep these pests below the danger point though occasionally poisoned baits may have to be used to control them. Cabbage leaves, sliced carrots or sliced potatoes lightly dusted with equal parts of Paris Green and flour have been found to be effective when placed where these larvae ean find them and feed on them.

No diseases of any importance have been noted yet in our California tobacco fields. Root rot has been observed and in every case was directly traceable to either careless or excessive use of water.

None of the troubles here noted save the jack rabbits and squirrel nuisance has been the cause of death of any considerable number of plants. However, any damage to a part of a leaf makes perfect curing of it nearly impossible. The leaf that has been injured however slightly by grasshoppers, tobaceo worms, cutworms, or flea beetles must go in a grade lower than the leaf not so injured and so in the aggregate a considerable loss may occur. The grower's aim should be to produce a perfect leaf, therefore every effort should be made to control pests of all kinds. 


\section{APPENDIX}

Daniel S. Neuman, of Napa, California, a man of wide experience in all phases of tobacco production and curing, offers the following information and comment:

When writing a thesis for the degree of Master of Chemistry in the University of San Vladimir, Kief, Russia, I chose the subject of qualitative analysis of nicotines found in different varieties of European and Asiatic grown tobaccos. The first part of this thesis was devoted to the study of the history of tobacco in those countries. Using only the original sources, I found that:

"Tobaceo was first introduced into Spain from the American continent in the 16th century. From there it was easy to trace its rapid spread to France, Austria, Hungary, the Balkan States, Greece, Turkey, and thence eventually to Russia. Tobacco was also grown in Great Britain in considerable quantities in the 17 th century, but its cultivation was prohibited after a few years, so as not to injure the American industry (America being at that time a colony of Great Britain).

It is easy to understand why Spain, France, Austria and Hungary ceased to be tobacco growing countries as all of them adopted a government monopoly on all tobacco products, and the maximum fixed price for home-grown tobacco was so small, that it hardly paid a planter to continue to cultivate it."'

One of the main ingredients of tobacco is Nicotianin (tobacco camphor). This crystallizes easily at the ordinary temperature of the air.

Nicotina, an alkaloid similar to conia (a strong narcotic), does not exist in tobacco in solid form at the ordinary temperature. It can be found only in an oily volatile state. Nor does it exist in infusions of tobacco, and only a mere trace of it can be found in decoctions. But when tobacco is burned as in smoking, the following substances are formed:
1. Nicotianin
2. Empyreumatic oil
3. Carbonate of ammonia
4. Soot
5. Different gases

The common name generally applied to these combined substances is Nicotine. This point is very important as the samples of Turkish tobacco grown in different countries show a great variation in the percentage of these ingredients. To have a perfect aromatic tobacco the percentages have to be evenly balanced. For 
instance, Havana, Cuba, tobaceo not grown under canvas contains such a small percentage of tobacco camphor that it lacks aroma and is of little commercial value. On the other hand, Harana tobacco grown under canvas (which protects it from the chemical action of the sun's fierce rays) retains all its volatile constituents, thus developing the aroma and flavor which are so much prized by smokers the world over. No tobacco today commands so high a price as Havana raised under canvas.

A good deal of difference can be noticed in tobacco grown in different districts in Turkey, as the amount of essential constituents varies according to the latitude. Tobacco grown in the northern districts is much more delicate and of finer quality.

Advice to cover with paper bags the tobacco blossoms, on plants selected for seed in order to prevent cross-pollinization is very good in part, but my experience proves that many of the seeds do not fully mature if covered continuously, as the paper covering prevents proper ventilation of the seed capsules. The writer adopted the following plan :

1. Cover with paper bags until the capsules are entirely formed, then, replace bag with a double thickness of cheese cloth.

2. When the seeds have entirely matured, dip the whole seed crown in bichloride of mercury solution 1 to 30,000 , to destroy tobacco dust insects, etc.; dry thoroughly at once, and seal in a paper sack previously pricked with a pin for ventilation.

The writer used the following method:

The collected leaves were placed in piles about ten inches high on tables in a cool, well ventilated room, and left until they commenced to sweat (evaporation of sap). This usually required from thirty to thirty-eight hours. (At the same time this wilts the tobacco leaves and renders them so flexible that there is less danger of breaking or damaging them when they are being strung.)

Having strung and fastened the tobacco to the sticks the sticks were placed in the shade where they were kept for three or four days, until the leaves began to turn yellow, when they were removed to the open racks for sun curing. 